\title{
ASPECTOS BIOLÓGICOS DA NEUROCISTICERCOSE: ALTERAÇõES DO LIQÜIDO CEFALORRAQUIDIANO
}

\author{
A. SPINA-FrançA *
}

Atribui-se a Rumler, em 1558, o primeiro registro da presença de cisticerco no sistema nervoso central (SNC) do homem. Desde então e até o fim da primeira década do século XX mais de três centenas de casos de neurocisticercose foram descritos ${ }^{35}$. Em sua maioria correspondem êsses casos a uma fase de diagnóstico anatômico. Os conhecimentos adquiridos sôbre a neurocisticercose resultavam do estudo anátomo-patológico e o diagnóstico era estabelecido post mortem ${ }^{13}$.

A partir dessa época, o diagnóstico em vida da afecção foi-se tornando cada vez mais comum, mediante o emprêgo de recursos paraclínicos exame radiológico (cisticercos calcificados) e exame do líqüido cefalorraquidiano - ou após biopsia durante intervenções cirúrgicas.

Cabe aos dados fornecidos pelo exame do LCR o papel mais relevante no diagnóstico em vida da neurocisticercose. Segundo Guccione ${ }^{11}$, o achado do parasito ou de fragmentos de sua parede no líqüido cefalorraquidiano (LCR) já fôra referido em fins do século passado (Hartmann) e no início dêste (Stertz). A raridade dêstes achados tira-lhes o valor prático ${ }^{6}$. Entretanto, da infestação do SNC pelo cisticerco podem resultar alterações do LCR que, em suas linhas gerais, constituem a sindrome liquórica da neurocisticercose ${ }^{19}$ de grande utilidade diagnóstica. Entre os elementos que constituem essa sindrome destacam-se pela sua importância a eosinofilorraquia e a positividade da reação de fixação do complemento para cisticercose.

Segundo Cuadra 9, cabem a Grund e a Waterhause, em 1913 e independentemente, os registros dos dois primeiros casos nos quais havia eosinofilorraquia e em cuja necropsia foram encontrados cisticercos no SNC. Desde então, vários autores passaram a salientar a importância do achado. Rizzo, em 1931, chegou a considerar a eosinofilorraquia elemento suficiente para o diagnóstico da neurocisticercose, opinião compartilhada por Pacifico, logo depois ${ }^{26}$. Em 1935, Lange estudou detalhadamente o assunto, concluindo pela importância da eosinofilorraquia no diagnóstico dessa afecção ${ }^{17}$. Não

Trabalho da Clinica Neurológica da Fac. Med. da Univ. de São Paulo (Prof. A. Tolosa), apresentado ao II Congresso Neurológico Argentino e I Reunião do Grupo Internacional de Trabalho de Neurologia Tropical, patrocinado pela Federação Mundial de Neurologia (Buenos Aires, 1 dezembro 1961): * Assistente extranumerário. 
lhe deu, porém, valor absoluto, pois pode ela decorrer de outras causas e sua ausência não infirma o diagnóstico. Esta opinião é mantida pela maioria dos autores.

Maior importância no diagnóstico liquórico $t \in m$ a positividade da reação de fixação do complemento para cisticercose (RFC). Segundo Magalhães ${ }^{22}$, foi introduzida em 1909 por Weinberg; êste autor não conseguiu demonstrar a presença de anticorpos no sôro de paciente com cisticercose generalizada, embora tivesse feito a reação empregando diversos antígenos, entre os quais o líqüido de vesícula parasitária retirada do mesmo paciente. Moses, no Brasil (1911), empregando como antígeno o extrato aquoso de Cysticercus cellulosae foi o primeiro a demonstrar a positividade da reação de fixação do complemento no sôro de três pacientes com cisticercose e no LCR de um dêles. Em 1919, Guccione introduziu o emprêgo do extrato alcoólico de cisticercos como antígeno, cuja utilização em nosso meio foi difundida por Pessoa, Silveira e Corrêa (1927 a 1929). Este é o antigeno mais largamente empregado até hoje, tendo sofrido sucessivas modificações, conforme historiam Reinlein, Trigueros e Alcalde ${ }^{23}$ em 1951, ao preconizarem a purificação prévia do cisticerco pela lavagem em acetona. Em 1957, Magalhães 21 introduziu nôvo tipo de antígeno, o extrato metílico de cisticercos prèviamente tratados por benzeno.

Deve-se a Lange a introdução da RFC na rotina do exame do LCR; em 1936, êste autor demonstrou a especificidade relativa da reação quando praticada no LCR e sua utilidade para o diagnóstico biológico da neurocisticercose ${ }^{18}$. Hoje, é opinião geral que a positividade da RFC no LCR é o meio mais seguro para o diagnóstico da afecção, conforme se depreende da análise de levantamentos sôbre o assunto feitos em regiões onde a incidência da neurocisticercose é elevada. Entre outros, podem ser lembrados os estudos de Asenjo (Chile) 2, Napanga (Peru) ${ }^{24}$, Escobar ${ }^{10}$, Nieto ${ }^{25}$ e Lombardo e Mateos ${ }^{20}$ (México), Iizuka ${ }^{12}$ e Isamat de la Riva ${ }^{13}$ (Espanha), Zozulya e Sklyarenko (URSS) ${ }^{41}$. Em nosso meio, em sucessivos trabalhos tem sido realçado o valor da RFC para o diagnóstico liquórico da neurocisticercose $1,7,19,23,27,32$.

As possibilidades diagnósticas da positividade da RFC e das alteraçōes citológicas do LCR serão analisadas neste trabalho, sendo utilizados exclusivamente casos nos quais foi comprovada a infestação do SNC pelo cisticerco. Em complemento e para discutir alguns dos aspectos biológicos suscitados pela análise, serão apresentados os aspectos principais do proteinograma do LCR na afecção, porque permitem avançar os conhecimentos quanto à sua patogenia ${ }^{33}$.

\section{MATERIAL E METTODOS}

Em 62 pacientes portadores de neurocisticercose comprovada pelo exame necroscópico ou por biopsia durante o ato cirúrgico foram estudadas as alterações do LCR de maior importância diagnóstica. Os casos foram acompanhados na Clínica Neurológica da Faculdade de Medicina da Universidade de São Paulo e foram selecionados entre aquêles revistos por Canelas ${ }^{8}$, em 1961. 
Os aspectos liquóricos estudados compreendem o exame citológico e a RrC. Paralelamente, em 8 casos, foi estudado o proteinograma do LCR e, em 39, a RFC foi feita também no sôro sangüineo (sôro).

A amostra de LCR estudada corresponde ao primeiro exame feito no paciente. Para os casos em cuja evoluçāo liquórica surgiram aspectos de interêsse são referidos os exames subsequientes.

O LCR foi colhido da cisterna magna em 43 casos, de um dos ventrículos laterais em 11 e, por punção lombar, em 8. A contagem global dos elementos celulares foi feita em câmara de Fuchs-Rosenthal e os resultados são expressos pelo número de leucócitos por $\mathrm{mm}^{3}$; a contagem especifica foi feita em esfregaço corado pelo método de Leishman (resultados em valores percentuais). A RFC foi feita segundo a técnica de Kolmer 14. O proteinograma do LCR foi estudado por eletroforese em papel e seus resultados interpretados em relação aos padrões estabelecidos no laboratório desta Clínica ${ }^{* 3}$.

\section{RESULTADOS}

No quadro 1 são referidos os resultados do exame citológico e da RFC; os do exame eletroforético das proteínas do LCR constam do quadro 2.

Em 40 casos o número de leucócitos no LCR era superior a 3 por $\mathrm{mm}^{3}$. Dêstes casos com pleiocitose, o total de células não era superior a 10 por $\mathrm{mm}^{3}$ em 7; variava entre 10 e 50 em 25 casos; entre 50 e 1C0, em três; era maior que 100 em 5 . O tipo celular predominante em todos êsses casos foi representado por elementos da série linfomononuclear; em 23 casos havia células eosinófilas.

$O$ teor de células eosinófilas variou entre 1 e $5 \%$ em 13 casos; entre 6 e $10 \%$ em 7 e, em três, era maior que 10\%. O maior teor encontrado foi de $30 \%$ (caso 29).

No liquiido cefalorraquidiano a RFC foi positiva em 41 casos; no sôro foi positiva em 21 dos 39 casos em que esta reação foi feita.

Foram encontradas alteraçōes de um ou mais dos exames estudados nas amostras de LCR de 50 pacientes (quadro 3). Caracterizava-se o quadro liquórico de 21 pacientes pela associação de pleiocitose, eosinofilorraquia e positividade da RFC; em 10, por pleiocitose e positividade da RFC. Em 7 casos havia sòmente pleiocitose e, em 2, pleiocitose e eosinofilorraquia. Em 10 casos a positividade da RFC se apresentava como dado isolado.

Dos 39 casos em que foi feita a RFC no LCR e no sôro, o resultado se mostrou semelhante em ambos os materiais em 26 casos; assim, em 18 a RFC era positiva no sôro e no LCR e, em 8, negativa. A RFC era positiva no LCR e negativa no sôro em 10 casos e em 3 negativa no LCR e positiva no sôro. Em 2 dêstes últimos (casos 36 e 47) nāo havia pleiocitose liquórica e em um (caso 57) havia pleiocitose não acompanhada de eosinofilorraquia.

Em todos os casos estava alterado o perfil eletroforético das proteinas do LCR. O aumento do teor de $\gamma$-globulina representou a principal alteração encontrada e repercutia de modo desigual sôbre o teor das demais frações. Assim é que a préalbumina estava ausente em 4 casos e teor de albumina diminuido em 3 (casos 37,53 e 59). Igualmente, achavam-se diminuidos os teores liquóricos das globulinas $\alpha-_{1}$ em um paciente (caso 59), $a_{2}$ no de 3 (casos 35,53 e 59) e $\beta$ em todos, com exceção de um em que era normal (caso 55).

\section{COMENTARIOS}

As alterações do LCR representam o aspecto biológico da neurocisticercose que tem sido mais amplamente estudado; é o valor diagnóstico dos achados liquóricos que tem justificado a maioria das investigações. Em 
vista disso será seguida essa orientação, analisando-se de início o significado do quadro citológico do LCR e da positividade da RFC na neurocisticercose; suas possibilidades diagnósticas serão estudadas a seguir. Alguns dos aspectos biológicos da reação inflamatória do LCR decorrentes da afecção serão considerados através da análise de peculiaridades de alguns casos. Finalmente, êsses aspectos serão analisados mediante os resultados do estudo do proteinograma do LCR na afecção.

1 - Citologia - É comum haver pleiocitose liquórica na neurocisticercose (2/3 dos casos no material analisado). Sua intensidade costuma ser pequena, não ultrapassando a cifra de 50 leucócitos por $\mathrm{mm}^{3}$ na maioria dos casos. Entre as células predominam elementos da linhagem linfomononuclear, ao lado dos quais podem ocorrer polinucleares neutrófilos e células eosinófilas.

A eosinofilorraquia foi observada em $50 \%$ dos casos com pleiocitose. Geralmente nāo se encontram células eosinófilas quando o número de leucócitos no LCR é normal e sua ocorrência costuma ser tanto maior quanto mais nitida a pleiocitose. Na maioria das vêzes seu teor não é superior a $10 \%$; em apenas três dos casos apresentados foram verificados teores mais elevados.

É variável o tipo de células eosinófilas encontradas no LCR: desde formas polinucleadas, semelhantes às encontradas no sangue, até formas mononucleadas (elementos da linhagem histiocitária) ${ }^{17}$. Por vêzes são encontrados agrupamentos de granulações eosinófilas livres.

Uma vez que a granulação eosinófila encerra enzima capaz de destruir a histamina ${ }^{39}$, a intensidade da eosinofilorraquia permite avaliar o grau de liberação dessa substância. Esta liberação é devida ao caráter hiperérgico da reação desencadeada pelo parasito no SNC. As reaçōes dêste tipo costumam ser inespecíficas e ocorrem em diversos tipos de processos patológicos, especialmente naqueles de natureza inflamatória. Esta particularidade tira à eosinofilarraquia o caráter diagnóstico patognomônico anteriormente admitido; na prática, pode ser encontrada em outras afecções do SNC ou de seus envoltórios, em especial naquelas de tipo agudo. Em geral, nestas condições, além de o exame do LCR oferecer outros elementos capazes de encaminhar ao diagnóstico, a presença de células eosinófilas é eventual e em número reduzido, podendo desaparecer ràpidamente. Recentemente ainda Lafon e col.16 apresentaram revisão detalhada do assunto.

A eosinofilorraquia tem sido eventualmente encontrada em outras parasitoses do SNC, como a esquistossomose e a equinococose ${ }^{34}$; entretanto, o caráter localizado da reação que estas afeç̧ões costumam determinar, com formação de granulomas e rara participação dos envoltórios, confere à cisticercose a primazia entre as afeç̧ōes parasitárias do SNC que costumam ser acompanhadas de eosinofilorraquia. Na cisticercose é mais comum a participação meníngea no mecanismo de defesa, em vista do que resulta pleiocitose liquórica, da qual participam, com freqüência e por longo tempo, as células eosinófilas. 


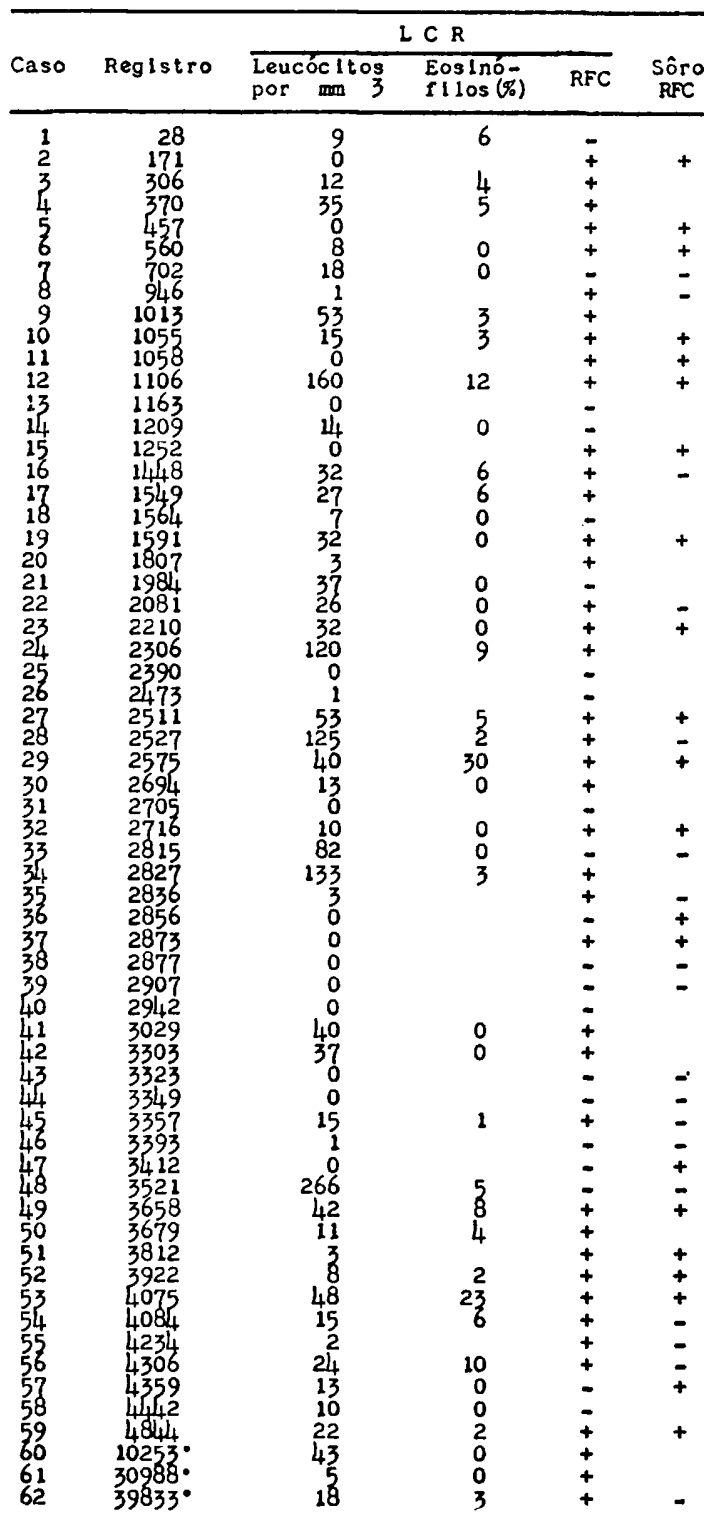

Quadro 1 - Resultados dos exames no LCR e no sôro. A amostra de LCR foi colhida de um dos ventriculos laterais nos casos $1,5,13,21,37,39,42$, 43, 44, 46 e 61 e por punção lombar nos casos 9, 14, 22, 24, 34, 41, 48 e 62. Nos demais o LCR foi colhido por puncão suboccipital. Legenda: RFC, reação de fixação do complemento para cisticercose; positiva (+), negativa (-). Para identificação dos acsos é referido o registro do paciente na enfermaria ou no ambulatório (*) da Clinica. 


\begin{tabular}{|c|c|c|c|c|c|c|c|c|}
\hline & \multirow{3}{*}{$C$ aso } & \multirow{3}{*}{$\begin{array}{c}\text { Proteinas } \\
\text { totais }\end{array}$} & \multicolumn{6}{|c|}{ Frações protêicas (\%) } \\
\hline & & & \multirow{2}{*}{$\begin{array}{c}\text { Pré- } \\
\text { albumina }\end{array}$} & \multirow{2}{*}{ Albumina } & \multicolumn{4}{|c|}{ Globulinas } \\
\hline & & & & & $\alpha_{1}$ & $\alpha_{2}$ & $\beta$ & $\gamma$ \\
\hline 35 & $\ldots$ & 25 & & 55,5 & 3,5 & 4,5 & 6,5 & 30,0 \\
\hline 37 & & 30 & & 37,4 & 7,9 & 7,4 & 12,1 & 35,2 \\
\hline 45 & $\cdots$ & 40 & & 56,0 & 5,0 & 10,8 & 11,2 & 17,0 \\
\hline 48 & .. & 20 & & 54,5 & 4,3 & 8,7 & 13,0 & 19,5 \\
\hline 53 & $\ldots \ldots \ldots \ldots$ & 20 & 1,0 & 41,0 & 3,0 & 4,0 & 11,0 & 40,0 \\
\hline 55 & $\cdots$ & 20 & 3,0 & 46,3 & 4,4 & 5,0 & 16,3 & 25,0 \\
\hline 57 & $\ldots \ldots \ldots \ldots$ & 30 & 1,2 & 45,3 & 5,2 & 7,2 & 13,6 & 27,5 \\
\hline 59 & $\ldots \ldots \ldots \ldots$ & 35 & 2,0 & 42,0 & 2,0 & 4,0 & 10,0 & 42,0 \\
\hline
\end{tabular}

Quadro 2 - Proteinograma do LCR em 8 casos. Proteinas totais em mg por $100 \mathrm{ml}$. Para as diversas fraçōes protêicas são referidos os teores parcentuais respectivos.

\begin{tabular}{cccc}
\hline No de casos & Pleiocitose & Eosinofilorraquia & $R F C$ positiva \\
\hline \hline 21 & + & + & + \\
10 & + & + & + \\
2 & + & & \\
7 & + & & + \\
10 & & & \\
\hline & & & \\
\hline Quadro 3 - Quadro liquórico nos 50 casos que apresentavam & alteracóos nos exames estudados.
\end{tabular}

2 - Imunologia - Ao lado da resposta inespecifica, representada pela liberação de histamina, a reação do SNC e seus envoltórios na neurocisticercose costuma ter um caráter imunitário especifico, havendo formação de anticorpos. A presença dêstes pode ser demonstrada por reações de fixação do complemento e de precipitação. Esta última é menos usada, foi introduzida por Trawinski e desenvolvida por Rothfeld; seu valor no diagnóstico liquórico foi estudado recentemente por Biagi e Tay, que aperfeiçoaram o antígeno e desenvolveram técnica adequada ${ }^{3}$.

Os anticorpos reconhecidos por meio da RFC têm especificidade apenas de grupo. O fenômeno imunitário desencadeado na cisticercose se aproxima daqueles encontrados na infestação por outros cestóideos, como o equinococo $^{32}$. O valor da reação no $L C R$ se deve à pequena freqüência em que se 
encontram no SNC cestóideos capazes de desencadear, da mesma forma que o cisticerco, reaçōes mais extensas, com participação m€ningea. É o caso de cenurose do SNC que, em certos meios ${ }^{15}$, é encontrada ao lado da neurocisticercose, tornando difícil o diagnóstico liquórico pelo estudo do fenômeno imunitário. Em meios como o nosso, nos quais é rara a infestação do SNC por tais cestóideos, a positividade da RFC no LCR representa o elemento principal para o diagnóstico biológico da neurocisticercose.

Compreende-se, pelo que se disse sôbre a especificidade do fenômeno imunitário, porque é mais restrito o valor da positividade da RFC no sôro; esta reação pode ser positiva nos casos de infestação por outros cestóideos, pode ser negativa na neurocisticercose e pode ser positiva pela presença do parasito em outras localizações.

A possibilidade da ocorrência no LCR de reações cruzadas, especialmente entre as reações de fixação do complemento para sífilis e para cisticercose torna aconselhável fazer as duas reações ao mesmo tempo, só se dando valor à positividade da RFC quando a reação de Wassermann fôr negativa ${ }^{27}$. Em casos duvidosos, o restante do quadro liquórico, especialmente o achado de eosinofilorraquia contribui para a elucidação diagnóstica ${ }^{31}$. Além disso, costuma-se fazer nesses casos, simultâneamente e pela técnica quantitativa ambas as reaçōes, dando-se valor àquela que fôr positiva nas maiores diluições da amostra ${ }^{29}$.

$\mathrm{O}$ emprêgo para a $\mathrm{RFC}$ de antígenos mais purificados reduz a proporção do problema das reações cruzadas, bem como a utilização de técnicas mais precisas para a $\mathrm{RFC}$ nos moldes, por exemplo, das reaçōes da hemólise parcial 21,30 .

3 - Diagnóstico liquórico da neurocisticercose - Entre as alterações do LCR na neurocisticercose, a presença de anticorpos específicos é o elemento que permite o diagnóstico. A eosinofilorraquia complementa êste último, mas é elemento de valor indicativo. Os resultados obtidos para os 62 pacientes estudados mostram que $\in \mathrm{m}$ cêrca de $2 / 3$ dos casos o exame do LCR permitia estabelecer com segurança o diagnóstico de neurocisticercose, porque a presença de anticorpos específicos foi demonstrada pela positividade da RFC. Em cêrca da metade dos casos em que esta era positiva, complementava o diagnóstico a cosinofilorraquia. Em dois casos esta foi verificada sem que houvesse positividade da RFC. O achado de células eosinófilas no LCR nesses casos permitia suspeitar da afecção mas não era suficiente para o diagnóstico.

A positividade da RFC e a eosinofilorraquia não são os únicos elementos da síndrome liquórica da neurocisticercose. Podem ocorrer outras alterações do LCR, na maioria inespecíficas, úteis para a avaliação do prognóstico e da evolução; merecem ser salientadas a hipertensão, a pleiocitose, a elevação do teor protêico, a diminuição da taxa de glicose e o comportamento de tipo parenquimatoso das reaçöes coloidais.

O encontro no craniograma de imagens sugestivas de cisticercos calcificados é precioso elemento para o diagnóstico ${ }^{40}$, embora seja maior a fre- 
qüência com que ocorrem alterações do LCR. No material levantado por Brotto ${ }^{7}$ em 1947 e no mesmo Serviço de onde provêm os casos analisados neste trabalho a presença de calcificações patológicas intracranianas foi demonstrada em $33 \%$ dos casos e o LCR apresentava alterações suficientes para o diagnóstico em 63\%. Na série de casos de neurocisticercose dêsse mesmo Serviço anteriormente analisada por nós ${ }^{32}$, o craniograma apresentava imagens sugestivas em $26 \%$ e o LCR alterações suficientes para o diagnóstico em 74\%. Êsses dados mostram que entre os recursos paraclínicos, o exame do LCR é aquêle que com maior probabilidade permite chegar ao diagnóstico de neurocisticercose.

4 - Variações do quadro liquórico - Entre as particularidades do quadro liquórico na neurocisticercose é de salientar que as alterações costumam ser mais intensas nas amostras subaracnóideas que nas colhidas no sistema ventricular. Assim, dos 11 casos desta série em que o LCR foi colhido de um dos ventrículos laterais, a amostra só estava alterada em 6; dêstes, a RFC foi positiva em 4 e, apenas em um foram encontradas células eosinófilas. Esse fato pode decorrer da maior intensidade da reação inflamatória nas proximidades do parasito ${ }^{36}$, transparecendo menos nas amostras de LCR situadas à montante de sua localização. Em vista disso, na cisticercose da fossa posterior, o LCR ventricular pode ser normal ou apresentar alterações discretas. Dos 7 casos desta série em que havia cisticercose da fossa posterior e em que foi estudado o LCR ventricular, não foram encontradas alterações liquóricas em 4 (casos 13, 39, 43 e 44); em um havia pleiocitose (caso 21) e sòmente em dois, pleiocitose e positividade da RCF (casos 42 e 61).

A evolução do quadro liquórico da neurocisticercose costuma ser variável e nem sempre acompanha a evolução clínica. Em geral, a evolução satisfatória é caracterizada pelo desaparecimento progressivo das alterações do LCR; se estas se mantiverem por longo tempo, o prognóstico é mais reservado, especialmente quando se instala hipoglicorraquia de intensidade progressivamente maior.

Por vêzes, o quadro liquórico característico aparece depois de periodo inicial de alterações inespecíficas; inicialmente costuma ocorrer reação celular e, ulteriormente, a formação de anticorpos específicos. Serve de exemplo a evolução liquórica do caso 57 (quadro 4).

\begin{tabular}{cccc}
\hline Data & Leucócitos $/ \mathrm{mm}^{3}$ & Eosinófilos (\%) & RFC \\
\hline \hline $3-6$ & 13 & 0 & - \\
$13-6$ & 12 & 0 & - \\
$20-6$ & 16 & 8 & + \\
\hline Quadro & $4-$ Evoluç̃o do quadro liquórico do caso $5 \%$
\end{tabular}


Parece que a reação inflamatória é devida aos produtos do catabolismo do parasito e à degeneração dos elementos que entram em sua constituição. Tanto é assim que a reação inflamatória é observada ao nível do poro de invaginação do cisticerco (ponto principal de eliminação de seus catabólitos) enquanto o parasito está vivo ${ }^{37}$. Após sua morte, a reação costuma ser mais intensa e mais difusa, em vista da livre drenagem do material que o constitui para o tecido circunjacente ${ }^{5,38}$. Esta exacerbação do quadro inflamatório pode transparecer no LCR. Bickerstaff e col. ${ }^{4}$ observaram que a rotura de cisticerco durante o ato cirúrgico desencadeia piora do quadro liquórico, que pode assumir um caráter meningítico, explicada pelo poder irritativo do líqüido da vesícula parasitária. No caso 43 (quadro 5),

\begin{tabular}{rccc}
\hline \multicolumn{1}{c}{ Data } & Leucócitos $/ \mathrm{mm}^{3}$ & Eosinófilos (\%) & $R F C$ \\
\hline $2-1$ & 0 & 4 & - \\
$15-1$ & 160 & + \\
\hline Quadro 5 - Evolução liquórica do caso 43. Rotura do cisícerco \\
durante o ato cirúrgico (8 janeiro).
\end{tabular}

ao ser removido cisticerco do IV ventrículo, houve rotura da sua vesícula. Uma semana depois havia acentuada pleiocitose liquórica, acompanhada de eosinofilorraquia e de positividade da RFC. $\dot{E}$ de notar que, neste caso, uma semana antes da operação, o LCR se achava normal. Esses episódios de agudização do quadro liquórico não costumam durar muito tempo; no caso 48 (quadro 6) houve também rotura da vesicula quando o parasito foi retirado do IV ventrículo e a intensa reação celular que se sucedeu, pràticamente desaparecera 20 dias depois.

\begin{tabular}{cccc}
\hline Data & Leucócitos $/ \mathrm{mm}^{3}$ & Eosinófilos (\%) & RFC \\
\hline $27-6$ & 266 & 5 & + \\
$11-7$ & 5 & & + \\
\hline Quadro $6-$ Evolução liquórica do caso 48. Rotura do cisticerco \\
durante o ato cirúrgico (20 junho $).$
\end{tabular}

A remoção cirúrgica do parasito costuma ser seguida de remissão das alterações do LCR nos casos de infestação única do SNC. No caso 54, as alterações do LCR tinham desaparecido cêrca de 4 meses depois da operação e, no caso 55, após cêrca de 2 meses. Em ambos, fôra removido cisticerco racemoso de um dos ventrículos laterais. Por outro lado, nos ca- 
sos de infestação múltipla, mesmo que pela cirurgia tenham sido removidos um ou mais cisticercos, não se observa tendência à regressão das alterações liquóricas, como ocorreu no caso 45 (quadro 7). Na necropsia dêste caso foi constatado que a neurocisticercose era generalizada e não apenas da fossa posterior, como inicialmente se admitiu e em virtude do que fôra a paciente operada.

\begin{tabular}{rccc}
\hline 1 & Leucócitos $/ \mathrm{mm}^{3}$ & Eosinófilos $(\%)$ & $R F C$ \\
\hline $27-3$ & 15 & 0 & 2 \\
$10-6$ & 39 & 1 & 4 \\
$13-9$ & 19 & 0 & 4 \\
$7-11$ & 30 & 2 & 4 \\
$29-11$ & 6 & 0 & 20 \\
$10-12$ & 12 & 0 & 20 \\
\hline
\end{tabular}

Quadro 7-Evolus̃ão do quadro liquórico do caso 45 (infestação múltipla). A positividade da $R F C$ é referida em unidades Kolmer.

5 - Alterações do proteinograma do $L C R$ - É pequena a importância das alterações da proteinorraquia total e do comportamento das reações coloidais na neurocisticercose; já as modificações do teor das frações protêicas do LCR mostram-se úteis para o estudo da afecção ${ }^{33}$. Por meio da eletroforese em papel são evidenciados distúrbios do equilíbrio protêico do LCR que permitem compreender melhor a patogenia da afecção.

O proteinograma do LCR na neurocisticercose é do tipo encontrado nos prceessos inflamatórios subcrônicos e nas fases iniciais dos de tipo crônico do SNC e seus envoltórios. A alteração fundamental é representada pelo aumento da $\gamma$-globulina; êste aumento costuma ser intenso e repercute em especial sôbre o teor de $\beta$-globulina, que se acha diminuído.

$O$ aumento da $\gamma$-globulinorraquia na neurocisticercose resulta da reação imuncpatológica local e permite ter idéia quanto à intensidade desta reação. $\dot{E}$ tanto maior quanto mais intensa fôr a participação dos elementos de defesa sediados no SNC e em seus envoltórios na luta contra o parasito. Êstes elementos, em sua maioria, fazem parte do sistema retículo-endotelial e podem ser responsabilizados pela produção da $\gamma$-glołulina. Ao que tudo indica, também na neurocisticercose, esta fração é a carreadora dos anticorpos específicos.

Ao mesmo tempo e através do comportamento das demais frações protêicas, especialmente da albumina e das globulinas $\alpha$, pode-se ter idéia quanto à intensidade das alteraçōes da barreira hêmato-liquórica provocadas pela afecção. 
Pela sua homogeneidade e pelo decurso, as alterações do proteinograma do LCR na neurocisticercose contribuem para o diagnóstico e para o contrôle da evolução. Nos 8 casos desta série em que foi feito o exame eletroforético das proteínas do LCR o teor de $\gamma$-globulina estava aumentaclo; em 7 havia diminuição do teor de $\beta$-globulina. O aumento de $\gamma$-globulina ocorre preccemente; por vêzes precede a formação de anticorpos específicos (caso 57) e regride mais lentamente que o desaparecimento dêstes. No caso 55, ainda havia aumento da reação $\gamma$-globulina por ocasião do segundo exame do LCR, quando haviam desaparecido as demais alterações.

Se a evciução do caso não fôr satisfatória, costumam acentuar-se as alterações do proteinograma do LCR. No caso 45, por ocasião do primeiro exame, o aumento de $\gamma$-globulina era pequeno; 7 meses depois e pouco tempo antes do óbito, era acentuado o aumento do teor dessa fração, representando o dôbro daquele $€$ videnciado por ocasião do primeiro exame.

\section{RESUMO}

Entre os aspectos biológicos da neurozisticercose, têm sido mais exploradas as alterações do líqüido cefalorraquidiano (LCR) em vista do seu valor diagnóstico. Para analisar os conhecimentos quanto ao quadro liquórico da afecção são apresentados os achados referentes a 62 casos acompanhadcs na Clínica Neurológica da Faculdade de Medicina da Universidade de São Paulo. Em todos êstes casos a infestação do sistema nervoso central (SNC) e/ou de seus envoltórios pelo cisticerco foi comprovada pela necropsia ou durante intervenção cirúrgica (biopsia).

A análise do material e da literatura sôbre o assunto permite as seguintes conclusōes:

1 - Entre o; exames complementares, o exame do LCR é aquêle que permite com maior freqüência o diagnóstico em vida da neurocisticercose. A demonstração da presença de anticorpos específicos é o elemento fundamental para o diagnóstico liquórico; a ecsinofilorraquia complementa êsse dado e tem valor sugestivo.

2 - $\mathrm{Na}$ neurocisticercose, a eosinofilorraquia costuma ser tanto mais intensa quanto mais nitida a pleiozitose liquórica; entretanto, a presença de células eosinófilas no LCR pode decorrer de outras causas e sua ausência não infirma o diagnóstico. A cosinofilorraquia permite avaliar a intensidade da reação hiperérgica desencadeada pelo parasito e possibilita orientar o diagnóstico em casos duvidosos.

3 - Na cisticercose há formação de anticorpos específicos, demonstráveis por meio de reações de precipitação e de fixação do complemento; esta última é a mais largamente utilizada. Oș anticorpos são semelhantes aos que ararecem no parasitismo por outros cestóideos. Quando localizados no 
SNC e/ou em seus envoltórios, são os cisticercos os cestóideos que, com maior freqüência e em maior intensidade, desencadeiam reações imunitárias, determinando o aparecimento de anticorpos específicos no LCR.

4 - A evolução do quadro liquórico é variável e nem sempre acompanha a evolução clínica. Quando esta é satisfatória, costumam desaparecer progressivamente as alterações do LCR; se estas se mantiverem por longo tempo, o prognóstico é mais reservado, especialmente quando aparece hipoglicorraquia.' Em alguns casos, após intervenções cirúrgicas há rápida remissão das alterações do LCR; provàvelmente isto ocorre nos casos em que a infestação do encéfalo era discreta, ou mesmo única. Quando ocorre rotura da vesícula parasitária durante a intervenção cirúrgica, o líqüido contido em seu interior acarreta exacerbação transitória das alterações do LCR.

5 - As alterações do proteinograma do $L C R$ na neurocisticercose são do tipo verificado em processos inflamatórios subcrônicos e crônicos do SNC e de seus envoltórios, caracterizando-se especialmente por aumento de $\gamma$-globulina. Este aumento está relacionado à intensidade da reação imunopatológica e provàvelmente é devido à produção local dessa globulina, que parece ser a carreadora dos anticorpos especificos. O aumento de $\gamma$-globulina é precoce, podendo preceder a formação dos anticorpos específicos e costuma regredir lentamente nos casos de evolução satisfatória. Quando a evolução é má, o teor dessa globulina costuma aumentar progressivamente.

\section{SUMMARY}

Biological aspects of neurocysticercosis: changes in the cerebrospinal fluid.

The CSF changes in neurocysticercosis have been extensively studied in view of their diagnostic importance. The CSF changes in 62 human cases of neurocysticercosis are presented. In all cases the diagnosis of cysticercosis was ascertained either by surgical procedure or by autopsy.

The following observations are made from the study of this material, and from the pertinent literature:

1 - More cases had their diagnosis made during life by the CSF examination alone than by any other procedure. The demonstration of specific antibodies in the CSF is the main diagnostic element. The presence of eosinophile cells is only suggestive of the diagnosis, and is complementary to the immunologic data.

2 - The occurrence eosinophile in the CSF is more pronounced in cases of higher total cell count. The presence of eosinophiles in the CSF may be secondary to other causes, and its absence does not invalidate the diagnosis of cysticercosis. The hyperergic reaction to the parasite can be evaluated through the eosinophile count, which contributes to the diagnosis in doubtful cases. 
3 - Specific antibodies are present in the CSF in human cysticercosis, demonstrated by complement fixation and precipitation tests, the former being used more often. The antibodies appearing in cestoid parasitism are similar as a general rule. The immune reaction to the Cysticercus cellulosae in the CNS is greater in frequency and intensity, as compared to the other cestoids.

4 - The CSF changes are variable and do not always follow the clinical progress. The improvement in the clinical picture usually is followed by progressive disappearence of the CSF changes. The prognosis is worse with persistence of the CSF changes, particularly with a low sugar content. After surgical excision of cysticerci the CSF changes occasionally disappear, probably due to a small degree of parasitism, totally removed by surgery. Extravasation of the vesicular fluid of a cysticercus during an operation induces transient increase in the CSF changes.

5 - The CSF protein electrophoresis pattern in neurocysticercosis is similar to the pattern observed in sub-chronic or chronic inflammatory processes of the CNS and its coverings. An increase in the $\gamma$-globulin fraction is found and it is related to the intensity of the immune reaction. This globulin fraction probably contains the specific antibodies and the possibility of local production of this globulin is to be considered. The rise in $\gamma$-globulin appears early in the disease, and may precede the formation of specific antibodies. It regresses slowly when the clinical progress is good. There is a progressive increase in cases of poor evolution.

\section{REFERENCIAS}

1. ALBERNAZ Filho, P. M. - Incidência da cisticercose do sistema nervoso central no Serviço de Neurologia da Escola Paulista de Medicina. Rev. paulista Med., 43:161 (agôsto) 1953. 2. ASENJO, A. - Setenta y dos casos de cisticercosis en el Instituto de Neurocirugia. Rev. Neuro-Psiquiat. (Lima), 13:337 (setembro) 1950. 3. BIAGI, F.; TAY, J. - A precipitation reaction for the diagnosis of cysticercosis. Amer. J. Tropical Med. a. Hyg., 7:63-65 (janeiro) 1958. 4. BICKERSTAFF, E. R.; SMALL, J. M.; WOOLF, A. L. - Cysticercosis of the posterior fossa. Brain, 79:622-634 (dezembro) 1956. 5. BRICENO, C. E.; BIAGI, F.; MARTINEZ, B. - Cisticercosis. Observaciones sobre 97 casos de autopsia. Prensa Med. Mexicana, 26: 193-197 (maio, 31) 1961. 6. BRINCK, G. - La Cisticercosis Cerebral (Estudio Anátomo-Patológico y Clínico). Tese, Santiago (Chile), 1940. 7. BROTTO, W. - Aspectos neurológicos da cisticercose. Arq. Neuro-Psiquiat. (São Paulo), 5:258-294 (setembro) 1947. 8. CANELAS, H. M. - Neurocisticercose: incidência, diagnóstico e formas clínicas. Arq. Neuro-Psiquiat. (São Paulo), 20:1 (março) 1962. 9. CUA-DRA, M. - Cisticercosis cerebral y eosinofilia raquidea. Rev. Neuro-Psiquiat. (Lima), 12:339-366 (março) 1949. 10. ESCOBAR, J. A. - Cisticercosis cerebral. Arq. Mexic. e Psiquiat., 1:149-167 (setembro-dezembro) 1952. 11. GUCCIONE, A. - La Cisticercosi del Sistema Nervoso Centrale Umano. Soc. Ed. Libraria, Milano, 1919. 12. IIZUKA, H. - Observaciones Clinicas sobre la Neurocisticercosis. Tese. Ed. Paz Montalvo, Madrid, 1961. 13. ISAMAT DE LA RIVA, F. - Cisticercosis Cerebral. Vergara S.A., Barcelona, 1957. 14. KOLMER, J. A.; SPAULDING, E. H.; ROBINSON, H. W. - Approved Laboratory Technic, 5: ed. Appleton-Century-Crofts Inc., New York, 1951, págs. 797-855. 15. KUPER, S.; MENDELOW, H.; PROCTOR, N. S. F. Internal hydrocephalus caused by parasitic cysts. Brain, 81(II):235-242, 1958.16. 
LAFON, R.; LABANGE, A.; RIBSTEIN, M.; BARJON, M. C. - Les éosinophiles du liquide céphalo-rachidien: la meningite aiguë curable à éosinophiles. Rev. Ncurol., \$7:466-481 (dezembro) 1957. 17. LANGE, O. - Sôbre as células eosinj́filas do liquido céfalo-raquidiano. Rev. de Neurol. e Psiquiat. de São Paulo, 1:421-434 (julhodezembro) 1935. 18. LANGE, O. - O liquido cefalorraquidiano na cisticercose do sistema nervoso central. Rev. de Neurol. e Psiquiat. de São Paulo, 2:3-11 (março) 1936. 19. LANGE, O. - Sindromo Iiquórico da cisticercose ensé́alomeningea. Rev. de Neurol. e Psiquiat. de São Paulo, 6:35-48 (fevereiro) 1940. 20. LOMBARDO, L.; MATEOS, J, H. - Cerebral cysticercosis in Mexico. Neurology, 11:824-828 (setembro) 1931. 21. MAGALHĀES, A. E. A. - A reação de fixação do complemento para cisticercose no liquido cefalorraquidiano. Emprêgo de novo antigeno por método quantativo. Arq. Neuro-Psiquiat. (São Paulo), 15:183-189 (setembro) 1957. 22. MAGAlHAEs, A. E. A. - Contribuição para o Estudo da Reação ce Fixação do Complemento com Antígeno de Cysticercus cellulosae. Tese, Ribeirão Prêto (São Paulo), 1957. 23. MONTEIRO SALLES, F. J. - Cisticercose Cerebral. Tese, São Paulo, 1934. 24. NAPANGA, J. - Reacción de fijación del complemento en la cisticercosis. Rev. Med. Hosp. Obrero (Lima), 2:121-126, 1553. 25. NIETO, D. — Cysticercosis of the nervous system. Diagnosis by means of the spinal fluid complement fixation test. Neurology, 6:725-738 (outubro) 1556. 26. PACIFICO, A. - Cisticercosi cerebrale e prove biologiche. Boll. Soc. Ital. Biol. Sper., \&:1, 1933. 27. PUPO, P. P.; CARDOSO, W.; REIS, J. B.; PEREIRA DA SILVA, C. - Sôbre a cisticercose encefálica. Estudo clínico, anátomo-patológico, radiológico e do líquido cefalorraquidiano. Arq. Assist. Psicop. do Estado de São Paulo, 10 e 11 (janeiro-dezembro) 19451946. 28. REINlein, J. M. A.; TRIGUEROS, E. A.; AlCALDE, S. O. — The study of cerebrospinal fluid in diagnosis of cysticercosis of the central nervous system. Bull. Inst. Medical. Res. (Madrid), 4:65-76 (abril-junho) 1951. 29. REIS, J. B. Contribuição do laboratório para o diagnóstico da cisticercose encefálica. Rev. paulista Med., 43:164-165 (agôsto) 193̄3. 30. REIS, J. B.; BEI, A. - A reaçāo de fixação do complemento para o diagnóstico da sifilis e da cisticercose no líquido cefalorraquidiano pela técnica de Wadsworth, Maltaner e Maltaner. Rev. paulista Med., 5£:459-478 (dezembro) 1958. 31. REIS, J. B.; BEI, A.; DINIZ, H. B. - Dificuldade no diąnóstico diferencial entre cisticercose $€$ ncefálica e neurolues. Arq. Neuro-Fsiquiat. (São Paulo), 7:156-164 (junho) 1949. 32. SPINA-FRANÇA, A. - Cisticercose do sistema ncrvoso ccntral: consideraçces sôbre 50 casos. Rev. paulista Med., 48: 59-70 (janeiro) 1956. \$3. SPINA-FRANÇA, A. - Valor do exame eletroforético das proteinas do líqüido cefalorraquidiano na cisticercose do sistema nervoso central. Arq. Neuro-Psiguiat. (São Paulo), 18:301-34C (dezcmbro) 1930. 34. SPINA-FRANCA, A.; AMATO NETTO, V. - O líaüido cefalcraquidiano na esquistossomose mansoni. Rev. paulista Med., 46:274-281 (abril) 1955. 35. TRELLES, J. O.; LAZARTE, J. A. - Cisticercosis cerebral: estudo clínico, histopatológico y parasitológico. Rev. Neuro-Psiquiat. (Lima), suplemento, 1941. 36. TRELLES, J. O.; RAVENS, R. - Estudios sobre la neurocistizercosis: II. Lesiones vasculares, meningeas, ependimarias y neuróglicas. Rev. Neuro-Psiquiat. (Lima), 16:241-271 (setembro) 1953. 37. TRELLES, J. O.; ROCCA, E.; RAVENS, R. - Estudios scbre la neurocisticercosis: I. Sobre la fina estructuia de la membrana vesicular cística y racemosa. Deduciones patológicas. Rev. Neuro-Fsiquiat. (Lima), 15:1-35 (marco) 1952. 38. TRELLES, J. O.; ROEDENBECK, S. D. - Estudios sobre neuiocisticercosis: III. Formas clinicas poco frecuentes de cisticercosis cerebral. Rev. Neuro-Psiquiat. (Lima), 17:15-26 (março) 1S54. 29. VERCAUTEREN, R. - The properties of the isolated granules from blood eosinophiles. Enzymologia (Acta Bicoatalytica), 16:1-13 (abril) 1953. 40. ZACLIS, J. - Contribuição radiológica para o diagnóstico da neurocisticercose. Rev. paulista Med., 43:165 (agôsto) 1953. 41. ZOZULYA, Y. A.; SKLYARENKO, N. I. - The importance of complement fixation reactions with the cysticercoid antigen in the diagnosis of cysticercosis of the brain. Vop. Neirokir. (Moscou), 22(5):28-33 (setembro-outubro) 1958.

Clinisa Neurológic: - Hosp:tal das Clinicas da Faculdade de Medicina, Universidade de São Paulo - Caixa Postal 3461 - São Paulo, Brasil. 